\title{
Papers
}

\section{Financial cost of social exclusion: follow up study of antisocial children into adulthood}

\author{
Stephen Scott, Martin Knapp, Juliet Henderson, Barbara Maughan
}

\begin{abstract}
Objectives To compare the cumulative costs of public services used through to adulthood by individuals with three levels of antisocial behaviour in childhood. Design Costs applied to data of 10 year old children from the inner London longitudinal study selectively followed up to adulthood.

Setting Inner London borough.

Participants 142 individuals divided into three groups in childhood: no problems, conduct problems, and conduct disorder.
\end{abstract}

Main outcome measures Costs in 1998 prices for public services (excluding private, voluntary agency, indirect, and personal costs) used over and above basic universal provision.

Results By age 28, costs for individuals with conduct disorder were 10.0 times higher than for those with no problems $(95 \%$ confidence interval of bootstrap ratio 3.6 to 20.9) and 3.5 times higher than for those with conduct problems (1.7 to 6.2). Mean individual total costs were $£ 70019$ for the conduct disorder group (bootstrap mean difference from no problem group £62 898; £22 692 to £117 896) and £24 324 (£16 707; £6594 to £28 149) for the conduct problem group, compared with $£ 7423$ for the no problem group. In all groups crime incurred the greatest cost, followed by extra educational provision, foster and residential care, and state benefits; health costs were smaller. Parental social class had a relatively small effect on antisocial behaviour, and although substantial independent contributions came from being male, having a low reading age, and attending more than two primary schools, conduct disorder still predicted the greatest cost.

Conclusions Antisocial behaviour in childhood is a major predictor of how much an individual will cost society. The cost is large and falls on many agencies, yet few agencies contribute to prevention, which could be cost effective.

\section{Introduction}

The term "conduct disorder" refers to a persistent and pervasive pattern of antisocial behaviour in childhood or adolescence. ${ }^{1}$ Typical behaviours include disobedience, tantrums, fighting, destructiveness, lying, and stealing. Conduct disorder is the commonest psychiatric disorder in childhood, with a prevalence of $7 \%$ in boys and 3\% in girls'; it is also the commonest reason for referral of children and adolescents to mental health services. ${ }^{3}$

Conduct disorder is strongly associated with social and educational disadvantage. It occurs four times more often in families with unskilled occupations than in professional families²; reading difficulties are common, and many children leave school without qualifications or are permanently excluded..$^{4}$ The antisocial behaviour tends to persist $-40 \%$ of 8 year olds with conduct disorder are repeatedly convicted of crimes such as theft, vandalism, and assault in adolescence. ${ }^{6}$ The misuse of drugs and alcohol is widespread. Looking back, the continuity is even stronger, as $90 \%$ of repeating juvenile offenders had conduct disorder in childhood. ${ }^{6}$ In adulthood these individuals continue offending and have erratic employment patterns in unskilled jobs, violent relationships with partners, and few friends. ${ }^{5}$ They do not participate in mainstream society and remain socially excluded.

Few direct studies have looked at the economic costs of conduct disorder or its consequences. ${ }^{7}$ Related studies suggest that costs are high. In the United States the cost for crimes committed by a typical juvenile delinquent (under 18) was estimated at $\$ 80000$ $\$ 325000$ ( $\$ 56000-£ 232$ 000). ${ }^{8}$ Between ages 19 and 24 a typical adult criminal costs a further $\$ 1.2 \mathrm{~m}$. Victim costs were by the far the greatest part of this total. Dropping out early from school added \$243000$\$ 388000$ to age 24 , heavy drug use a further $\$ 150$ 000-\$360 000. Rescuing a high risk youth from this typical life path was estimated to save $\$ 1.7 \mathrm{~m}$ $\$ 2.3 \mathrm{~m}^{8}{ }^{8}$

In the United Kingdom the Audit Commission reported the expenditure incurred by young offenders. Identifying them costs the police $£ 1200$ and successful prosecution a further $£ 2500$. A week in a local authority secure unit costs $£ 3450$. $^{9}$ Our own pilot study, of children aged 4-8 referred with conduct disorder, found that the mean extra cost was $£ 15282$ a year (range $£ 5411-£ 40896$ ). Of this, 31\% was borne by families, $31 \%$ by education services, $16 \%$ by the NHS, $15 \%$ by state benefit agencies, $6 \%$ by social services, and less than $1 \%$ by the voluntary sector. ${ }^{10}$

In the United Kingdom there has been growing recognition of the costs of antisocial behaviour and social exclusion originating in childhood. A parliamentary select committee and a major independent inquiry

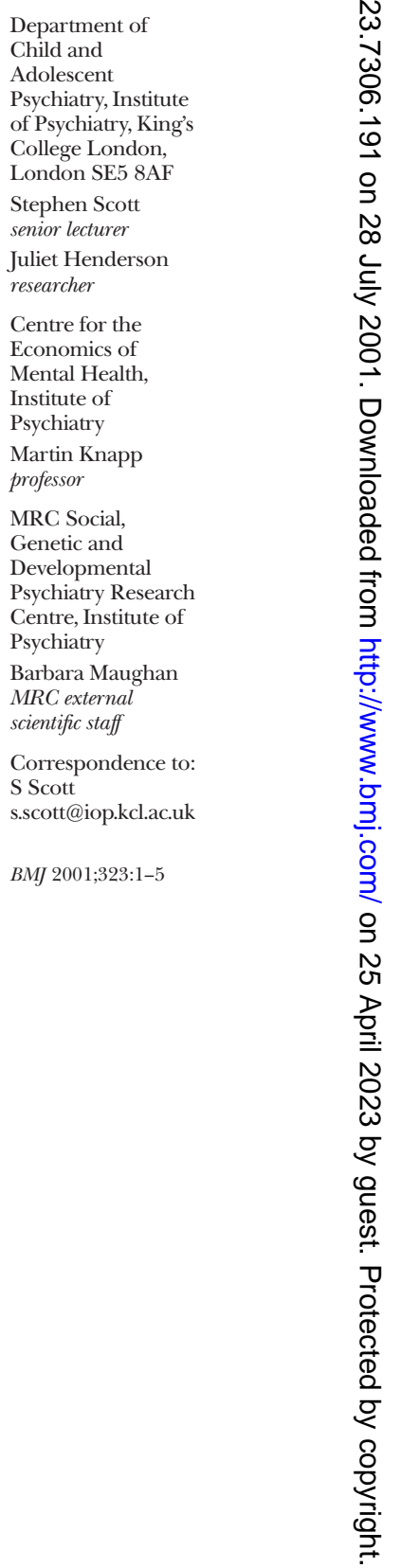


Table 1 Study groups, defining three levels of antisocial behaviour at age 10 years

\begin{tabular}{|c|c|c|c|}
\hline & No problems $(n=65)$ & $\begin{array}{c}\text { Conduct problems } \\
\qquad(\mathrm{n}=61)\end{array}$ & $\begin{array}{c}\text { Conduct disorder } \\
\qquad(\mathrm{n}=16)\end{array}$ \\
\hline No $(\%)$ of original screened sample $(n=1689)$ represented by group* & $1368(81.0)$ & $155(9.2)$ & $47(2.8)$ \\
\hline Screen positive for teacher rated emotional and behavioural problems & No & Yes† & Yest \\
\hline Diagnosis of conduct disorder by clinician on parent interview & No & No & Yes \\
\hline
\end{tabular}

${ }^{*}$ Conduct groups oversampled; children with emotional problems and no antisocial behaviour were excluded.

tWith predominance of antisocial problems.

concluded that unless there were adequate specialised services for the mental health needs of children, the economic and social costs would be considerable later on. ${ }^{112}$ The Audit Commission has called for better information on resources spent on children's mental health and has recommended that agencies commission children's services jointly. ${ }^{3}$ To plan services effectively, however, information is necessary on the long term costs of disorders, the range of agencies involved, and how costs vary according to the severity of problems. We aimed to determine the costs to the public sector incurred to age 28 in dealing with children with different levels of antisocial behaviour and to examine childhood predictors of long term cost; in particular, we aimed to discover how much antisocial behaviour adds to cost once personal characteristics have been taken into account.

\section{Participants and methods}

Inner London longitudinal study

We applied costs to data from the inner London longitudinal study, an epidemiological study of psychiatric problems and attainment in people from a disadvantaged inner London borough. ${ }^{13}$ The study began in 1970 when the children were 10 and tracked their progress to their late 20 s. All 10 year olds $(n=2281)$ attending state primary schools in the borough were screened using the Rutter teacher questionnaire. ${ }^{14}$ Two subsamples were selected for intensive study: a random 1 in 12 sample of the total population and a 1 in 2 sample of children who had screened positive for emotional and behavioural problems. Among the 1689 non-immigrant children screened, 228 of the 249 selected were successfully assessed. Parental interviews covered 33 child behaviours, and diagnoses were assigned by clinicians. Children were tested individually with the Neale reading test. ${ }^{15}$

Individuals who had emotional problems when screened at age 10 (119 children, $7 \%$ of original sample) were excluded as this study concerned antisocial behaviour. The remaining participants were divided into three mutually exclusive subgroups, reflecting different levels of severity of childhood antisocial behaviour: no behavioural or emotional problems on screening or parental interview; high scores on screening, with a predominance of antisocial problems but no disorder on parental interview; and high scores on screening, with a diagnosis of conduct disorder on parental interview (table 1 ). At follow up in 1986-8 data were available on 65 of $80(81 \%), 61$ of 73 $(84 \%)$, and 16 of $22(73 \%)$ participants, respectively. The participants' mean age was 27.7 (SD 1.27) years.

Investigator based follow up interviews included measures of housing; educational history; psychosocial functioning as an adult, including work and marital history (adult personality functioning assessment ${ }^{16}$; psychiatric history as an adult and service contacts (past history schedule of present state examination) ${ }^{17}$; and alcohol problems (schedule for affective disorders and schizophrenia-lifetime version). ${ }^{18}$ The period covered for special educational provision, foster and residential care, and hospital contacts included childhood before age 10. Estimation of service use was based on these retrospective accounts, the reliability of which is good for factual information. ${ }^{19}$ Official criminal records were searched.

\section{Costing methods}

We calculated costs for each individual across six domains: foster and residential care in childhood, special educational provision, state benefits received in adulthood, breakdown of relationship (domestic violence and divorce), health, and crime. We allocated costs for every service reported as used above the basic provision prevailing at the time, whether or not utilisation seemed to arise from antisocial behaviour. For example, extra remedial teaching was costed but basic schooling was not. Table 2 gives further examples of services used and costs applied. We applied costs only if there was good quality information about the use of services. We applied 1998 price levels for services as they would have been provided in 1998, using the best approximations to long run marginal opportunity costs. We took unit costs from national sources for health and social care services, criminal justice, and benefit receipts. ${ }^{20-22}$ We calculated other costs from first principles using agencies' data, ensuring that their coverage (for example, of travel, supervision, and overheads) was consistent with the national sources.

We could not assess many costs because the original survey was not designed for an economic study. No costs were allocated for use of social services, voluntary organisations, primary health care, lost employment, divorce (other than public legal costs), undetected crime (which is several times more common than detected crime), ${ }^{5}$ the costs to victims of crime (which can also be large), ${ }^{82}$ parents' or partners' use of services arising from the participant's behaviour, indirect costs to families, or psychological impact, such as the distress and lack of friends of individuals with antisocial behaviour or the unhappiness of their siblings. For some events the dataset did not include frequency, so only one episode was costed (foster care, residential child care, exclusion from school, divorce, recipient of domestic violence, abortion). Abortion and domestic violence were only costed for index female participants, not partners of male participants. No assessment was made of economic contributions such as paying income tax.

\section{Analysis strategy}

As the data for costs were highly skewed, in addition to $t$ tests of differences not assuming equality of variances, 
we used bootstrap estimation to derive $95 \%$ confidence intervals of differences and ratios between groups. We used bootstrap multiple regression to determine childhood predictors of total cost, ${ }^{23}$ applying inverse probability sampling weights to allow for the original two phase sample design and effects of attrition at the interviewing stages in childhood and adulthood. We used Stata software.

\section{Results}

Costs of each domain-Table 3 shows the mean individual costs for each domain; the total individual cost ranged from $£ 0$ to $£ 379$ 292. Crime was the costliest domain in all the groups and constituted almost two thirds of the total cost in the conduct disorder group. For the two conduct groups the next three costliest domains were education, foster and residential care, and benefits. For all the groups health service costs were the fifth largest and relationship costs the smallest.

Cost differences between groups-The conduct disorder group cost 10 times more than the no problems group and the conduct problem group over three times more (table 4). The extra costs of both conduct groups were not only due to crime but also to higher use of services across all domains (except relationships in the conduct disorder group, where there were only two female participants, so the costs for domestic violence were lower).

Personal characteristics and educational attainment in childhood in relation to cost-Other childhood characteristics were also associated with variations in cost (table 5). Being male led to higher costs. Being from a family of lower socioeconomic status, having a low reading age, and attending more than two primary schools led to significantly higher costs with $t$ tests but just missed significance using bootstrap tests, where lower values for confidence intervals were negative.

Childhood predictors of total cost-After allowance for personal characteristics and educational variables in childhood, multiple regression analysis showed that conduct disorder and not group membership pre-
Table 2 Numbers (percentages) of participants in each group using main services, and costs applied

\begin{tabular}{|c|c|c|c|c|}
\hline Service* & $\begin{array}{c}\text { No } \\
\text { problems } \\
(\mathrm{n}=65)\end{array}$ & $\begin{array}{c}\text { Conduct } \\
\text { problems } \\
(\mathrm{n}=61)\end{array}$ & $\begin{array}{l}\text { Conduct } \\
\text { disorder } \\
(n=16)\end{array}$ & $\begin{array}{c}\text { Cost applied ( } £ \text { at } 1998 \\
\text { prices) }\end{array}$ \\
\hline \multicolumn{5}{|l|}{ Type of care } \\
\hline Foster & $2(3)$ & $2(3)$ & $0(0)$ & $408 /$ week $\times 26$ \\
\hline Residential home & 1(2) & $4(7)$ & $3(19)$ & $1461 /$ week $\times 26$ \\
\hline \multicolumn{5}{|l|}{ Education services } \\
\hline Remedial help at primary school & $4(6)$ & $11(18)$ & $1(6)$ & 9936/year $\times 1$ \\
\hline Remedial help at secondary school & $3(5)$ & $8(13)$ & $4(25)$ & $9936 /$ year $\times 1$ \\
\hline Permanently excluded & $0(0)$ & $3(5)$ & $1(6)$ & $7232 \times 1$ \\
\hline Social worker for truancy & $3(5)$ & $4(7)$ & $2(13)$ & $340 \times 1$ \\
\hline Adult literacy classes & $0(0)$ & $5(8)$ & $1(6)$ & $91 \times 1$ \\
\hline \multicolumn{5}{|l|}{ Benefits } \\
\hline Unemployment $\geqslant 5$ months & $1(2)$ & $21(34)$ & $4(16)$ & Variable \\
\hline Single parent with children & $3(5)$ & $4(7)$ & $0(0)$ & Variable \\
\hline \multicolumn{5}{|l|}{ Relationships } \\
\hline Violence from partner & $5(8)$ & $7(11)$ & $2(13)$ & $610 \times 1$ \\
\hline Divorce (legal aid) & $10(15)$ & $12(20)$ & $1(6)$ & $851 \times 1$ \\
\hline \multicolumn{5}{|l|}{ Health services } \\
\hline Hospital inpatient (child) & $8(12)$ & $18(30)$ & $7(44)$ & $1366 \times 1$ or 2 \\
\hline Psychiatric outpatient (child) & $0(0)$ & $3(5)$ & $3(19)$ & $2150 \times 1$ \\
\hline Psychiatric outpatient (adult) & $0(0)$ & $4(7)$ & $3(19)$ & $582 \times 1$ \\
\hline Psychiatric inpatient (adult) & $6(9)$ & $5(8)$ & $0(0)$ & $7560 \times 1$ \\
\hline Abortion or miscarriage & $13(20)$ & $11(18)$ & $0(0)$ & $371 \times 1$ \\
\hline \multicolumn{5}{|l|}{ Justice system } \\
\hline Convicted & $12(18)$ & $19(31)$ & $9(56)$ & Variable \\
\hline In prison & $1(2)$ & $3(5)$ & $4(25)$ & 641/week \\
\hline
\end{tabular}

*Non-comprehensive list.

dicted most cost (table 6). Conduct problems, sex, reading age, and number of primary schools attended made substantial independent contributions and parental socioeconomic status a smaller contribution. The extra cost of individuals who attended more than two primary schools was unrelated to antisocial behaviour in childhood and came almost entirely from crime. Costs for extra educational provision were lower.

\section{Discussion}

Antisocial behaviour at age 10 was a powerful predictor of the total cost of public services used by age

Table 3 Arithmetic mean of total costs of services (in £ at 1998 prices) used by individuals to age 28 according to group at age 10

\begin{tabular}{|c|c|c|c|c|c|c|c|c|c|}
\hline \multirow[b]{2}{*}{ Domains } & \multicolumn{3}{|c|}{ No problems } & \multicolumn{3}{|c|}{ Conduct problems } & \multicolumn{3}{|c|}{ Conduct disorder } \\
\hline & All $(n=65)$ & $\begin{array}{c}\text { Females } \\
(\mathrm{n}=30)\end{array}$ & $\begin{array}{l}\text { Males } \\
(\mathrm{n}=35)\end{array}$ & All $(n=61)$ & $\begin{array}{l}\text { Females } \\
(n=23)\end{array}$ & Males $(n=38)$ & All $(n=16)$ & $\begin{array}{l}\text { Females } \\
(\mathrm{n}=2)\end{array}$ & $\begin{array}{l}\text { Males } \\
(n=14)\end{array}$ \\
\hline Education & 1508 & 1107 & 1851 & 7524 & 6377 & 8219 & 12478 & 7243 & 13226 \\
\hline Health & 247 & 219 & 270 & 1237 & 881 & 1453 & 2178 & 994 & 2347 \\
\hline $\begin{array}{l}\text { Foster and residential } \\
\text { care }\end{array}$ & 1320 & 0 & 2451 & 3412 & 6625 & 1468 & 7647 & 0 & 8740 \\
\hline Relationships & 97 & 122 & 75 & 156 & 211 & 122 & 63 & 0 & 73 \\
\hline Benefits & 1710 & 821 & 2471 & 3391 & 3293 & 3450 & 2832 & 0 & 3237 \\
\hline Crime & 2541 & 53 & 4674 & 8604 & 5627 & 10406 & 44821 & 0 & 51224 \\
\hline Total cost & 7423 & 2322 & 11792 & 24324 & 23014 & 25118 & 70019 & 8237 & 78847 \\
\hline
\end{tabular}

Table 4 Mean differences and ratios between total individual costs (in $£$ at 1998 prices) by age 28 according to group membership at age 10

\begin{tabular}{lcccc} 
Group & Mean difference & $\begin{array}{c}\boldsymbol{t} \text { test } \\
(\text { significance })\end{array}$ & Bootstrap mean difference (95\% Cl) & Bootstrap ratio (95\% Cl) \\
\hline Conduct disorder versus no problem & 62597 & $4.31(\mathrm{P}<0.001)$ & $62898(22692$ to 117 896) & $9.95(3.56$ to 20.88) \\
\hline Conduct problem versus no problem & 16903 & $5.2(\mathrm{P}<0.001)$ & $16707(6594$ to 28 149) & $3.45(1.69$ to 6.17$)$ \\
\hline Conduct disorder versus conduct problem & 45695 & $3.07(\mathrm{P}=0.003)$ & $46193(3830$ to 102 510) & $3.04(1.14$ to 6.06) \\
\hline
\end{tabular}

Bootstrap estimation using 2000 repetitions, bias corrected. 
Table 5 Mean differences and ratios of total individual costs (in $£$ at 1998 prices) by age 28 according to personal characteristics and educational factors at age $10^{*}$

\begin{tabular}{|c|c|c|c|c|c|}
\hline & No & Mean difference & $\begin{array}{l}t \text { test (signifi } \\
\text { cance) }\end{array}$ & Bootstrap mean difference $(95 \% \mathrm{CI})$ & Bootstrap ratio $(95 \% \mathrm{CI})$ \\
\hline \multicolumn{6}{|l|}{ Sex } \\
\hline$\overline{\text { Male }}$ & 873 & 12297 & $9.78(\mathrm{P}<0.001)$ & 12339 (6 440 to 19057$)$ & 4.37 (2.17 to 8.32$)$ \\
\hline Female & 695 & & & & \\
\hline \multicolumn{6}{|c|}{ Parental social class } \\
\hline Low & 612 & 6218 & $4.00(P<0.001)$ & 6341 (-980 to 14820$)$ & $1.83(0.85$ to 3.28$)$ \\
\hline Hight & 955 & & & & \\
\hline \multicolumn{6}{|l|}{ Reading age } \\
\hline$<7.5$ years & 120 & 8235 & $2.99(P=0.003)$ & 8525 (-1 577 to 26457$)$ & $1.96(0.87$ to 3.93$)$ \\
\hline$\geqslant 7.5$ yearsł & 1426 & & & & \\
\hline \multicolumn{6}{|c|}{ No of primary school attended } \\
\hline$\geqslant 3$ & 144 & 11977 & $4.39(\mathrm{P}<0.001)$ & 12486 (-2 818 to 30859$)$ & $2.48(0.71$ to 4.80$)$ \\
\hline 1 or 2 & 1402 & & & & \\
\hline
\end{tabular}

Bootstrap estimation using 2000 repetitions, bias corrected.

*Irrespective of conduct group. Sample reweighted to represent screened population studied $(n=1567)$; numbers vary due to missing data.

†Registrar general's social classes I, II, and III non-manual versus III manual, IV, V, and unknown.

†Neale reading comprehension.

28. This remained true after allowing for being male, a poor reader, and raised in a family of lower socioeconomic status. Total costs increased steeply with increasing antisocial behaviour: individuals with conduct problems as rated by a teacher cost over three times as much and individuals with conduct disorder cost 10 times as much as those without conduct problems.

The extra costs in the antisocial groups fell on a wide range of agencies dealing with social exclusion. Criminal justice costs were by far the highest and could be higher today, as crime rates have increased. ${ }^{5}$ Education costs were second highest and could be higher now, as more children receive specialist services. Care costs were third highest but might be lower now because residential homes are used less, although unit costs are now higher and there has been an increase in specialist placements for foster care. Benefit costs were fourth highest. Health costs were low because only a small proportion of the children reached the mental health services; this is still true. ${ }^{2}$

\section{Limitations}

Several aspects of service use were not costed, and indirect costs were not assessed. Including these might have increased the total cost severalfold and be a better reflection of the "true" cost. Therefore the ratio of costs between groups and domains is an important measure.

The borough studied was relatively socially deprived, with high levels of antisocial behaviour ${ }^{13}$; however, rates of antisocial behaviour in youths in the
United Kingdom have since risen to comparable levels. $^{5}$

\section{Implications}

Antisocial behaviour in childhood often leads to lifelong social exclusion. ${ }^{5}$ It imposes considerable costs in childhood ${ }^{10}$ and high public expenditure and personal distress by adulthood. The impact on public spending is substantial. In our sample $2.8 \%$ of the population was classified with conduct disorder and a further $9.2 \%$ with conduct problems, values that are typical for the United Kingdom and United States. ${ }^{5}$ This $12 \%$ of the population accounted for around half of the public expenditure assessed.

There are effective interventions for antisocial behaviour in children, but they are seldom routinely available. Parent training programmes have been shown to have large effects in many university trials in the United States, ${ }^{24}$ and our own study showed they can be equally effective in routine clinical practice in the United Kingdom. ${ }^{25}$ Typical programmes cost $£ 600$ per child and are likely to save money in the longer term. ${ }^{25}{ }^{26}$ Complementing a family based approach, there are effective behaviour management and social skills programmes for primary schools..$^{27}$ In contrast, interventions for serious antisocial behaviour in teenagers are much less effective. ${ }^{5}$ Therefore there is a case for implementing effective early interventions with families and with children at school.

The current UK government has launched several initiatives to reduce antisocial behaviour and social

Table 6 Factors at age 10 predicting total cost (in $£$ at 1998 prices) by age 28 , determined by multiple linear regression analysis

\begin{tabular}{|c|c|c|c|c|}
\hline Variable & $\begin{array}{l}\text { Regression } \\
\text { coefficient }\end{array}$ & $\begin{array}{c}\text { Standardised } \\
\text { regression coefficient } \\
\beta\end{array}$ & $t$ test (significance) & Bootstrap regression coefficient $(95 \% \mathrm{Cl})$ \\
\hline Sex & 12406 & 0.29 & $12.2(P<0.001)$ & 12076 (6 022 to 20808$)$ \\
\hline Parental social class* & 3092 & 0.14 & $6.0(\mathrm{P}<0.001)$ & 3035 (408 to 6458$)$ \\
\hline Reading age $\dagger$ & 6730 & 0.19 & $7.2(P<0.001)$ & 6829 (1 757 to 12076$)$ \\
\hline No of primary schools attended & 14902 & 0.21 & $9.08(P<0.001)$ & 15226 (1 818 to 34049$)$ \\
\hline Conduct problems & 13090 & 0.18 & $7.8(\mathrm{P}<0.001)$ & 12987 (3 263 to 25449 ) \\
\hline Conduct disorder & 31372 & 0.23 & $10.3(P<0.001)$ & 31253 (7803 to 65334$)$ \\
\hline Residual constant & 7422 & & $2.8(P=0.003)$ & 7905 (-5 696 to 21035$)$ \\
\hline
\end{tabular}

Ordinary least squares regression adjusted $\mathrm{R}^{2}=0.26$. Bootstrap regression with 2000 repetitions, bias corrected.

${ }^{*}$ Registrar general's social classes I, II, and III non-manual; III skilled manual; IV and V; unknown.

†Neale reading comprehension above 130 months, 90-130, below 90 . 


\section{What is already known on this topic}

Children who show substantial antisocial behaviour have poor social functioning as adults and are at high risk of social exclusion

Costs are available for particular items of public service such as receiving remedial education or appearing in court

\section{What this study adds}

Costs of antisocial behaviour incurred by individuals from childhood to adulthood were 10 times greater for those who were seriously antisocial in childhood than for those who were not

The costs fell on a wide range of agencies

Reduction of antisocial behaviour in childhood could result in large cost savings

exclusion in high risk areas. The "surestart" programme targets children aged 0-3 years with "one stop shop" services for their parents. The "on-track" programme aims to prevent antisocial behaviour in 4-12 year olds and avoid crime later on. The "health action zones" have goals such as reducing exclusions in school, drug misuse, and early pregnancy. They are, however, confined to specific areas, often do not use proved interventions, and are short term.

Organisational barriers prevent effective service organisation. Many agencies are simply not aware that antisocial behaviour in childhood leads to high costs for them. Among agencies working with children (health, education, social services, and voluntary agencies) none is primarily responsible for antisocial behaviour, and few consistently use evidence based interventions. Health commissioners have little direct financial incentive to give priority to effective intervention because their service bears little of the long term cost. Mental health services for children in the United Kingdom lack the resources to oversee widespread implementation of effective interventions; spending was $£ 9$ per child in 1997-8. ${ }^{3}$ A well coordinated multiagency approach that used interventions of proved effectiveness could considerably reduce the costs of antisocial children when they are grown up.

We thank Jack Astin for statistical analysis. MK is also professor at the London School of Economics Health and Social Care, London School of Economics. JH is also researcher at the Centre for the Economics of Mental Health, Institute of Psychiatry.

Contributors: SS was a principal investigator, was responsible for planning and managing the project, selecting the information to which costs were applied and interpreting the results, and wrote the paper; he will act as a guarantor for the paper. MK was a principal investigator, was responsible for planning and organising the economics approach and data, managing the project, overseeing the analysis, and interpreting the results; he assisted in writing the paper and is also a guarantor. JH organised and collected the cost data and assisted with project development. BM codirected the original follow up and assisted with data analysis and interpretation, and writing the paper.

Funding: Mental Health Foundation; SS held a Wellcome training fellowship for part of the project.

Competing interests: None declared.

1 Scott S. Aggressive behaviour in childhood. BMJ 1998:316:202-6

2 Meltzer H, Gatward R, Goodman R, Ford T. The mental health of children and adolescents in Great Britain. London: Office for National Statistics, 2000

3 Audit Commission. Children in mind. London: Audit Commission, 1999.

4 Maughan B, Pickles A, Hagell A, Rutter M, Yule W. Reading problems and antisocial behaviour: developmental trends in comorbidity.J Child Psychol Psychiatry 1996;37:405-18.

5 Rutter M, Giller, Hagell A. Antisocial behavior by young people. Cambridge: Cambridge University Press, 1998

6 Farrington DP. The development of offending and antisocial behaviour from childhood: key findings from the Cambridge study in delinquent development. J Child Psychol Psychiatry 1995;36:929-64.

7 Knapp MRJ. Economic evaluations and interventions for children and adolescents with mental health problems. J Child Psychol Psychiatry 1997;38:3-25.

8 Cohen MA. The monetary value of saving a high risk youth. J Quant Criminol 1998:14:5-33.

9 Audit Commission. Mis-spent youth. London: Audit Commission, 1997

10 Knapp M, Scott S, Davies J. The cost of antisocial behaviour in younge children. Clin Child Psychol Psychiatry 1999;4:457-73.

11 House of Commons Health Committee. Child and adolescent mental health services. London: Stationery Office, 1997.

12 Mental Health Foundation. Bright futures: promoting children and young people's mental health. London: Mental Heath Foundation, 1999.

13 Maughan B. Growing up in the inner city: findings from the inner London longitudinal study. Paediatr Perinat Epidemiol 1989;3:195-215.

14 Rutter M. A children's behaviour questionnaire for completion by teachers: preliminary findings. J Child Psychol Psychiatry 1967;8:1-11.

15 Neale MD. Neale analysis of reading ability manual. London: Macmillan, 1958.

16 Hill J, Harrington R, Fudge H, Rutter M. Adult personality functioning assessment (APFA): an investigator-based standardised interview. $\mathrm{Br} \mathrm{J}$ Psychiatry 1989;155:24-35.

17 McGuffin P, Katz R, Aldrich, J. Past and present state examination: the assessment of "lifetime ever" psychopathology. Psychol Med $1986 ; 16: 461-5$

18 Endicott J, Spitzer RLA. Diagnostic interviews: the schedule for affective disorders and schizophrenia. Arch Gen Psychiatry 1978;35:837-44.

19 Rutter M, Maughan B, Pickles A, Simonoff E. Retrospective recal recalled. In: Cairns RB, Bergman LR, Kagan J, eds. Methods and models for studying the individual. London: Sage, 1998

20 Netten A, Dennett J, Knight J. Unit costs of health and social care Canterbury: Personal Social Services Research Unit, 1998.

21 Home Office. Information on the criminal justice system in England and Wales. Digest 2. London: HMSO, 1993.

22 Healey A, Knapp M, Astin J, Gossop M, Marsden J, Stewart D, et al. Economic burden of drug dependency: social costs incurred by drug users at intake to the national treatment outcome research study. Br J Psychiatry intake to the nation

23 Thompson SG, Barber JA. How should cost data in pragmatic randomised trials be analysed? BMJ 2000;320:1197-200.

24 Kazdin AE. Parent management training: evidence, outcomes, and issues. J Am Acad Child Adolesc Psychiatry 1997;36:10-8.

25 Scott S, Spender Q, Doolan M, Jacobs B, Aspland H. Multicentre controlled trial of parenting groups for childhood antisocial behaviour in clinical practice. BMJ 2001;323:194-8.

26 Greenwood PW, Model KE, Rydell CP, Chiesa J. Diverting children from a life of crime: measuring costs and benefits. Santa Monica: Rand, 1996.

27 Durlak JA. School-based prevention programmes for children and adolescents. London: Sage, 1997.

(Accepted 25 April 2001) 